\title{
Local anesthetics for brain tumor resection: current perspectives
}

\section{Jan-Willem Potters Markus Klimek}

Department of Anesthesiology, Erasmus MC, Rotterdam, The

Netherlands
Correspondence: Markus Klimek Department of Anesthesiology, Erasmus MC, Office H-I28I, 's-Gravendijkwal 230, 3015 CE Rotterdam, The Netherlands Email M.Klimek@erasmusmc.nl
This article was published in the following Dove Press journal: Local and Regional Anesthesia

\begin{abstract}
This review summarizes the added value of local anesthetics in patients undergoing craniotomy for brain tumor resection, which is a procedure that is carried out frequently in neurosurgical practice. The procedure can be carried out under general anesthesia, sedation with local anesthesia or under local anesthesia only. Literature shows a large variation in the postoperative pain intensity ranging from no postoperative analgesia requirement in two-thirds of the patients up to a rate of $96 \%$ of the patients suffering from severe postoperative pain. The only identified causative factor predicting higher postoperative pain scores is infratentorial surgery. Postoperative analgesia can be achieved with multimodal pain management where local anesthesia is associated with lower postoperative pain intensity, reduction in opioid requirement and prevention of development of chronic pain. In awake craniotomy patients, sufficient local anesthesia is a cornerstone of the procedure. An awake craniotomy and brain tumor resection can be carried out completely under local anesthesia only. However, the use of sedative drugs is common to improve patient comfort during craniotomy and closure. Local anesthesia for craniotomy can be performed by directly blocking the six different nerves that provide the sensory innervation of the scalp, or by local infiltration of the surgical site and the placement of the pins of the Mayfield clamp. Direct nerve block has potential complications and pitfalls and is technically more challenging, but mostly requires lower total doses of the local anesthetics than the doses required in surgical-site infiltration. Due to a lack of comparative studies, there is no evidence showing superiority of one technique versus the other. Besides the use of other local anesthetics for analgesia, intravenous lidocaine administration has proven to be a safe and effective method in the prevention of coughing during emergence from general anesthesia and extubation, which is especially appreciated after brain tumor resection.
\end{abstract}

Keywords: brain tumor, craniotomy, local anesthesia, neurosurgery, scalp block

\section{Introduction}

Craniotomy for brain tumor resection is carried out frequently in neurosurgical practice. While about one-half brain tumors do not grow into neuronal tissue (like pituitary adenomas and meningiomas), the other half (e.g. oligodendrogliomas, astrocytomas, glioblastomas and metastases) do. Definitive cure of a tumor of this second group can be considered as impossible. On the other hand, it is known that a maximum of cytoreduction and tumor resection is associated with a better long-term survival. Therefore, these tumors are frequently resected by awake craniotomy with cortical (and subcortical) mapping, enabling a maximum of resection with a minimal risk of functional damage to the patient. ${ }^{1,2}$

submit your manuscript | www.dovepress.com 
If the patient is conscious and responsive at any time during the procedure, it is referred to as an awake craniotomy. An awake craniotomy can be carried out with three different forms of anesthetic care. In the sleep-awake-sleep technique, the patient is anesthetized during the placement of the skullpin head holder and the craniotomy whereafter consciousness must be regained in order to map cortical areas. Another option is to perform the procedure under monitored anesthetic care where the patient is mildly sedated to control anxiety and pain. Finally, the awake-awake-awake technique involves no sedation but only requires analgesia and special attention to non-pharmacological interventions such as hypnosis. ${ }^{3}$ In all awake craniotomy techniques, the use of local anesthetics is mandatory.

Neurosurgical procedures cause more pain than anesthesiologists expect, ${ }^{4}$ and post-craniotomy pain is not always well understood. ${ }^{5}$ However, clinicians have become more aware of the incidence and intensity of post-craniotomy pain. There is a large variation in the occurrence of postoperative pain and the requirement of analgesic medication in neurosurgical patients. Pain scores have a large variation ranging from a visual analog score of approximately 15 to more than 60 in two large studies. ${ }^{6,7}$ In a recent review of 26 studies assessing different aspects of postcraniotomy pain, 15 studies reported pain percentages in the first two postoperative days up to $60 \%-96 \%{ }^{5}$ It is unclear why this great variation of the incidence of postoperative pain exists in craniotomy patients. Attributable factors could be the perioperative opioid and analgesic regiment used, the exact moment of the first postoperative pain score and the composition of the neurosurgical population. A recent review studied several factors such as age and gender, surgical site, surgical technique, psychological factors and tumor characteristics, but the results are conflicting and inconclusive. ${ }^{8}$ The surgical site has turned out to be the only reliably identified factor: infratentorial surgery tends to be more painful and requires a higher cumulative opioid dose than supratentorial surgery, possibly because of the surgical-induced stretch and trauma of the neck muscle mass. ${ }^{9}{ }^{10}$ A review by de Gray and Matta provides further details about the pathogenesis of postoperative pain. ${ }^{10}$

The treatment of postoperative pain in neurosurgery is characterized by a balance between swift neurological assessment and the prevention of sedation, hypercapnia and opioid side effects such as vomiting on one side and patient comfort and the prevention of hypertension on the other side. Although opioids are frequently used in nonneurological surgery, their side effects raise caution to use these drugs in neurosurgical patients. Interestingly, these theoretical adverse effects have not been observed in studies using opioids. ${ }^{11}$ Nevertheless, post-craniotomy pain should be treated by multimodal pain management where several classes of drugs are combined with local anesthesia. ${ }^{11,12}$ Since patientrelated factors that can predict the occurrence of serious postoperative pain are not known, it is recommended to provide on-demand analgesics that need to be administered with minimal delay to all craniotomy patients. ${ }^{6}$ If an opioid drug is necessary, intermittent intravenous morphine provided on a medium- or high-care postoperative unit or via a patient-controlled system may be an effective option with less side effects compared to codeine or tramadol. ${ }^{12,13}$

Besides acute postoperative pain, craniotomy patients are prone to develop chronic post-craniotomy headache where the incidence varies between $0 \%$ and $65 \%{ }^{9,14} \mathrm{Chronic}$ pain can not only develop at the site of the incision but also develop as a moderate pressure sensation involving the entire head. In one study, $18 \%$ of the patients developed a severe throbbing sensation associated with nausea and vomiting. ${ }^{15}$ Several preoperative factors associated with the development of chronic headache have been identified, such as depression, anxiety and temporomandibular disorders. ${ }^{16}$

Locoregional anesthesia has been shown to have an additional value in craniotomy patients, independent of the anesthesia technique used. ${ }^{17}$ In the intraoperative phase, locoregional anesthesia diminishes the autonomic responses during the application of the skull-pin placement ${ }^{18,19}$ as well as during dural closure and skin closure, ${ }^{19}$ which due to the lack of a sensory innervation of the brain tissue itself are much more painful than tumor resection. Even under general anesthesia and after an opioid was administered, heart rate and blood pressure can increase by $15 \%$ and $43 \%$, respectively, after application of the Mayfield clamp. ${ }^{20}$ This effect can be largely diminished by preoperative application of local anesthesia, via either a scalp block or local infiltration, ${ }^{20,21}$ leading to a more hemodynamically stable anesthesiological course.

In awake craniotomy patients, the use of local anesthesia is the cornerstone of the procedure and has been established as a standard of care. ${ }^{21-23}$ If the local anesthesia is effective, no other analgesic drugs are necessary during the whole procedure. However, additional sedation is commonly used during craniotomy and closure, the steps of the procedure where the cooperation of the patient is not required. This combination enables a comfortable emergence and adequate analgesia during the regain of consciousness. The combination of sedation and local anesthesia has also been proven effective 
in the pediatric population. ${ }^{24,25}$ Sedation during craniotomy can be done with propofol or dexmedetomidine alone, and is much more a comfort measure than a medical need. The combination of local anesthesia with sedation has been used successfully in patients with a relative contraindication for a "typical" awake craniotomy, like fragile patients and patients with a poor neurological status, too. ${ }^{26}$ However, in our practice, we would prefer to perform procedures in these groups of patients under general anesthesia because of the better anesthesiological control of the intraoperative situation.

It can be discussed whether there is a place for shortacting opioids like remifentanil just before the injection of the local anesthetics; it increases patient comfort by damping some of the pain intensity of the local injections. On the other hand, the same injections are routinely performed without additional opioids in patients who need to be sutured after minor head traumas.

Regarding the additional value of local anesthetics for the postoperative phase of all craniotomy procedures, the use of regional anesthesia leads to lower pain scores and a reduction of opioid consumption in the early postoperative period. ${ }^{27}$ Local anesthetics can be injected as a dedicated regional scalp (or nerve) block or as a diffuse local infiltration of the surgical field. Studies using scalp blocks have been meta-analyzed. In an analysis published in 2013, seven studies with a total of 320 patients were systematically analyzed out of 20 studies that investigated the effect of regional scalp blocks. ${ }^{27}$ Several authors performed the scalp blocks at different time points of the perioperative course: a scalp block was performed preoperatively, before incision and after wound closure. The analysis showed an overall reduction in pain score 1 hour postoperatively (mean difference: $-1.61,95 \%$ confidence interval: -2.06 to $-1.15, P<0.001)$. A reduction in pain scores up to 8 hours for a preoperative scalp block and up to 12 hours with a postoperative blockade was observed. Application of a scalp block reduced morphine consumption, although this effect was small $(\mathrm{n}=6$ trials, standardized mean difference: $-0.79,95 \%$ confidence interval: -1.55 to $-0.03, P=0.04) .{ }^{27}$

Studies using local infiltration instead of application of a regional skull block were analyzed in a meta-analysis by Hansen et al. ${ }^{28}$ In total, there were five randomized trials including a total of 249 patients: Bloomfield et al described infiltration with bupivacaine $0.25 \%$ pre- and postoperatively showing a significant reduction in pain scores immediately on admission on the PACU that wears off after 1 hour. ${ }^{19}$ Other studies in this review looked at the effect of infiltration before suturing and skin closure using either ropivacaine $0.75 \%$ or bupivacaine $0.5 \%$. They found that infiltration reduces morphine consumption in the early postoperative period. ${ }^{29}$ Another study using ropivacaine $0.75 \%$ could not replicate this effect, but patients in the intervention group (with local anesthesia) showed significantly reduced pain scores in the early postoperative period..$^{30}$

A recent study using a mixture of lidocaine and ropivacaine addressed the question whether pre- or postoperative infiltration is more effective in reducing postoperative pain. The authors found lower pain scores and a reduction of morphine consumption in the group that received infiltration before incision. ${ }^{31}$ This supports the idea of "preemptive analgesia" by local anesthetics due to inhibition of the painsignal transmission. However, despite this weak support for local infiltration, there is an urgent need for more scientific trials addressing this issue.

For infratentorial craniotomies, a recent randomized trial showed that the scalp block blunts the hemodynamic response better during application of the skull-pin. Patients also had a slightly lower pain intensity score in comparison to local infiltration only. Postoperative morphine consumption was equal in both groups. ${ }^{32}$

Several studies addressed the effect of local anesthesia on the development of chronic post-craniotomy pain. Batoz et al found in a randomized trial that postoperative local infiltration with ropivacaine significantly reduces persistent pain 2 months after craniotomy. ${ }^{30}$ In a larger study with the same design, however, this effect was not found to be significant, ${ }^{33}$ leaving the effect of local infiltration on the development of chronic pain uncertain.

One recent study found beneficial effects of intravenous lidocaine in craniotomy patients. Intravenous lidocaine has already been extensively described and reviewed, especially in visceral-abdominal surgery where it reduces pain in the early postoperative period..$^{34}$ In the study by Peng et al, craniotomy patients were randomized to receive a bolus (1.5 $\mathrm{mg} / \mathrm{kg}$ ) and a continuous infusion ( $2 \mathrm{mg} / \mathrm{kg} / \mathrm{h}$ ) of intravenous lidocaine or saline. No other local anesthetic application was used. The lidocaine group showed lower pain scores and a higher rate of absence of pain $(\mathrm{NRS}=0)$ in the early postoperative period. ${ }^{35}$ Further research is needed to answer the question how intravenous lidocaine compares to the application of local anesthesia in terms of postoperative pain and morphine requirement.

Taking this all together, there is sufficient support for the use of local anesthetics to prevent pain during awake craniotomy, to reduce pain and pain response in patients undergoing craniotomy under general anesthesia and to prevent chronic pain after craniotomy. 
At this point, the technique of the local anesthesia itself must be studied further: must it be injected as a direct nerve/ scalp block or is a local infiltration of the field sufficient, too?

\section{Innervation of the scalp and direct nerve block}

The scalp is innervated by six different nerves on both sides (Table 1 and Figure 1). Excellent anatomical reviews have been published before describing in detail the location of the nerves in relation to the surface anatomy. ${ }^{36-39}$ When applying a direct nerve block, several considerations need to be taken into account. While the landmarks where these nerves leave the skull are quite well defined, the area they cover shows an enormous variability. The supraorbital nerve has the medial iris as a reliable topographical landmark, where the location of the nerve is within $1 \mathrm{~mm}$ from the needle, small enough to be reached by a deposition of local anesthetic. ${ }^{40}$ The supratrochlear nerve can also be reliably blocked at the point where it exits the orbita and before it enters the corrugator muscle. ${ }^{41}$ The zygomaticotemporal branch of the trigeminal nerve shows a variation in anatomy and branches. It also has an intramuscular course in $50 \%$ of the cases. ${ }^{42}$ Although the innervated area of the scalp of this nerve branch is small, identifying the exact blocking site of this nerve can be difficult and varies in the literature.
The auriculotemporal nerve runs between a distance of 8 and $20 \mathrm{~mm}$ anterior to the origin of the helix, so the recommended injection site is $10-15 \mathrm{~mm}$ from this point taking care not to inject the superficial temporal artery or to block branches of the facial nerve. ${ }^{43}$ Both anatomical structures are of special importance in patients undergoing awake craniotomies, as injecting in the first can cause epileptic seizures and blocking the second can cause (temporary) loss of nerve function, which can be confusing, if the surgeon operates near to neurons controlling facial function. More variation can be observed in the occipital nerves arising from the spinal plexus ${ }^{44}$ where some authors advocate a precise localization of the two different nerves ${ }^{36,39}$ while others recommend a field block approach to block the occipital nerves. ${ }^{38}$ However, in many patients, both occipital nerves can be identified with ultrasound, ${ }^{45}$ too, which enables a direct nerve block. Recently, a new study describing the use of a maxillary block in craniotomy patients found better analgesia compared to a regional scalp block. ${ }^{46}$ This innovative approach relies on the retrograde spread of the anesthetic along the maxillary nerve, leading finally to a complete block of all branches of the ipsilateral trigeminal nerve.

\section{Application of a field block}

When applying a field block, both the sites of the pins of the Mayfield clamp and the site of the incision must be infiltrated

Table I Nerves innervating the scalp

\begin{tabular}{|c|c|c|c|c|}
\hline Nerve & Origin & Innervation & Anatomical landmarks & $\begin{array}{l}\text { Special pitfalls on } \\
\text { injection }\end{array}$ \\
\hline Supraorbital nerve & $\begin{array}{l}\text { Frontal nerve (ophthalmic } \\
\text { division of trigeminal nerve) }\end{array}$ & $\begin{array}{l}\text { Forehead to lambdoidal } \\
\text { structure }\end{array}$ & $\begin{array}{l}\text { Incisura supraorbitalis, right above } \\
\text { pupil in a straight forward-looking } \\
\text { patient }\end{array}$ & $\begin{array}{l}\text { Direct nerve injection } \\
\text { Eyelid injury } \\
\text { Orbital injection }\end{array}$ \\
\hline $\begin{array}{l}\text { Supratrochlear } \\
\text { nerve }\end{array}$ & $\begin{array}{l}\text { Frontal nerve (ophthalmic } \\
\text { division of trigeminal nerve) }\end{array}$ & Lower part of the forehead & $\begin{array}{l}\text { Medial corner of the orbita, few } \\
\text { millimeters lateral from the nasal } \\
\text { apex }\end{array}$ & Not applicable \\
\hline $\begin{array}{l}\text { Zygomaticotemporal } \\
\text { nerve }\end{array}$ & $\begin{array}{l}\text { Zygomatic nerve (maxillary } \\
\text { division of trigeminal nerve) }\end{array}$ & $\begin{array}{l}\text { Small area of forehead and } \\
\text { temporal areas }\end{array}$ & $\begin{array}{l}\text { Half way between the supraorbital } \\
\text { and the auriculotemporal nerve }\end{array}$ & Not applicable \\
\hline $\begin{array}{l}\text { Auriculotemporal } \\
\text { nerve }\end{array}$ & $\begin{array}{l}\text { Mandibular division of } \\
\text { trigeminal nerve }\end{array}$ & $\begin{array}{l}\text { Tragus, anterior portions } \\
\text { of the ear, posterior } \\
\text { portion of temple }\end{array}$ & $\begin{array}{l}\text { I } 5 \mathrm{~mm} \text { ventral from the tragus } \\
\text { of the ear. Close to arteria } \\
\text { temporalis superficialis, cranial } \\
\text { from the os zygomaticum }\end{array}$ & $\begin{array}{l}\text { Proximity of artery and } \\
\text { facial nerve. Intra- } \\
\text { articular injection }\end{array}$ \\
\hline $\begin{array}{l}\text { Greater occipital } \\
\text { nerve }\end{array}$ & $\begin{array}{l}\mathrm{C} 2 / \mathrm{C} 3(\mathrm{Cl}-\mathrm{C} 4) \text { spinal } \\
\text { nerves }\end{array}$ & $\begin{array}{l}\text { Posterior part of the scalp } \\
\text { to the vertex }\end{array}$ & $\begin{array}{l}\text { End of the medial third of a line } \\
\text { between protuberantia occipitalis } \\
\text { externa and the lower end of } \\
\text { processus mastoideus, close to } \\
\text { arteria occipitalis }\end{array}$ & Arterial injection \\
\hline $\begin{array}{l}\text { Lesser occipital } \\
\text { nerve }\end{array}$ & C2 spinal nerves & $\begin{array}{l}\text { Lateral area of the scalp } \\
\text { posterior to the ear }\end{array}$ & $\begin{array}{l}\text { Beginning of the lateral third of } \\
\text { a line between protuberantia } \\
\text { occipitalis externa and the lower } \\
\text { end of processus mastoideus }\end{array}$ & Not applicable \\
\hline
\end{tabular}

Note: Based on data from Kerscher et al..$^{36}$ 

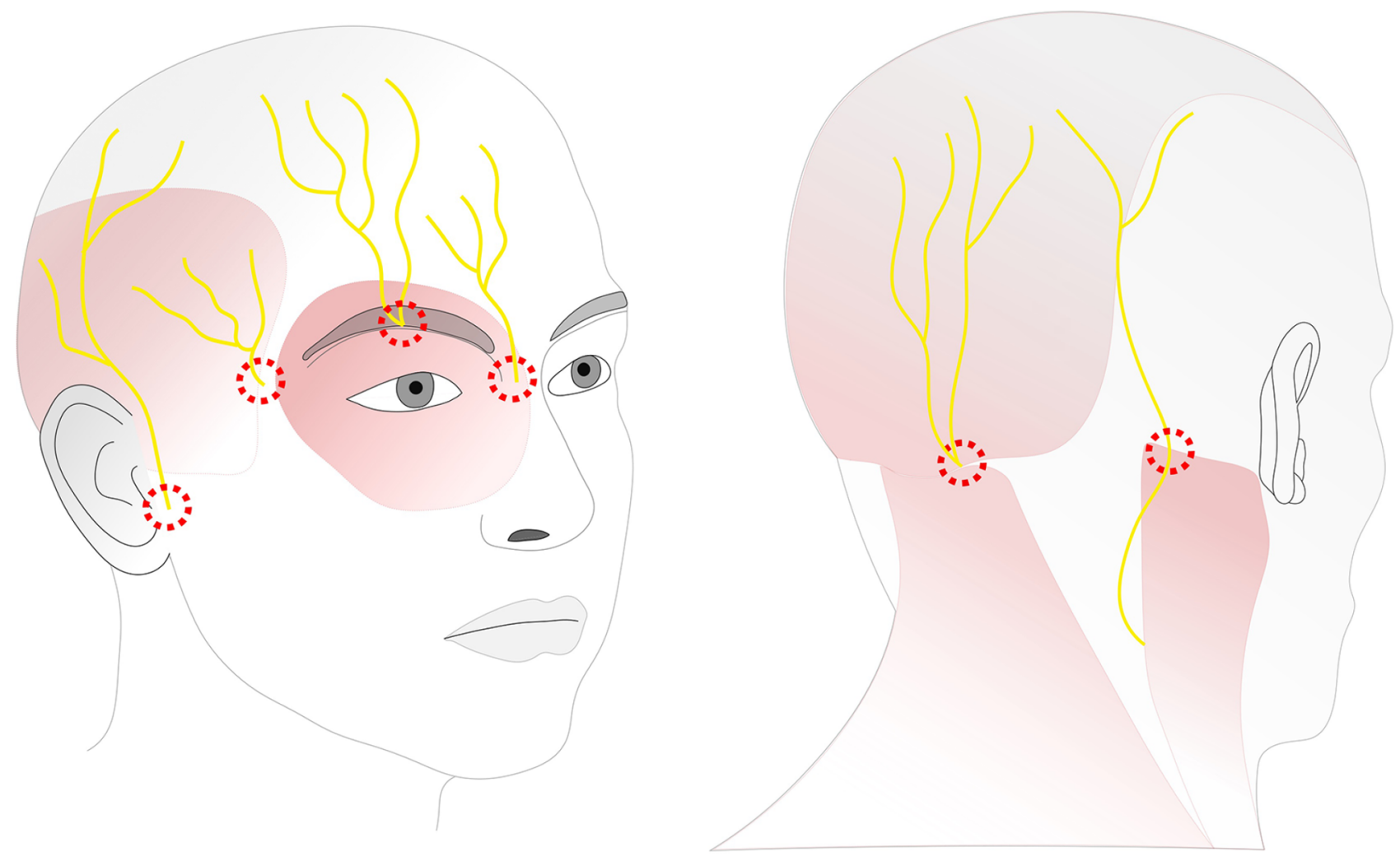

Figure I Sensory innervation of the skull and injection sites.

Notes: Nerves from left to right: auricotemporal nerve, zygomaticotemporal nerve, supraorbital nerve, supratrochlear nerve, greater occipital nerve and lesser occipital nerve. Injection sites are marked in red dotted circles.

with local anesthetics. To improve patient comfort, it is our practice to precede the injection of the local anesthetic by a bolus injection of a short-acting opioid (we use about 0.8 $\mu \mathrm{g} / \mathrm{kg}$ of remifentanil). For the Mayfield clamp, we routinely use an injection of $12-15 \mathrm{~mL}$ mixture of lidocaine $1 \%$ and bupivacaine $0.25 \%$ (final concentrations). Due to the fact that mostly there is only a short delay between the injection of the anesthetic and the placement of the clamp, we decided to add lidocaine for its fast onset. Epinephrine 1:200,000 can be safely added. We prefer the use of bupivacaine $0.25 \%$ over ropivacaine $0.75 \%$. Although the local anesthetic duration of bupivacaine with added epinephrine and ropivacaine is comparable ${ }^{29}$ and microvascular changes are identical, ${ }^{47}$ the cumulative dose of local anesthetic is lower when equal volumes of either bupivacaine $0.25 \%$ or ropivacaine $0.75 \%$ are used.

For anesthesia of the incision site, an injection of up to $30 \mathrm{~mL}$ of bupivacaine $0.375 \%$ combined with adrenaline $1: 200,000$ is used. In our practice, the anesthetist prepares the local anesthetics, but the responsible neurosurgeon himself injects the local anesthetics to prevent misinterpretation between the planned surgical incision and clamp sites and the anesthetized scalp areas. To prevent local anesthetic toxicity, we recommend this technique only for patients with a minimal weight of $50 \mathrm{~kg}$ in order to avoid a bupivacaine dose exceeding $3 \mathrm{mg} / \mathrm{kg}$. Mixing lidocaine and bupivacaine does not have a synergistic (supra-additive) effect on cardiotoxicity. ${ }^{48}$

Similar to other blocks, the same precautions must be taken into consideration when applying a cranial nerve block. Careful aspiration and slow injection to avoid intravascular injection are mandatory. Furthermore, a direct intraneural injection, which will cause immediate severe pain, must be stopped as soon as the patient complains. This risk is especially high in case of the supraorbital nerve block due to its anatomical position. When injecting to block the supraorbital nerve, care must be taken to prevent injury to the eyelid. When blocking the auriculotemporal nerve, injection in the temporomandibular joint, the superficial temporal artery and the facial nerve is a hazardous pitfall. The incidence of a transient facial nerve palsy after blockade of the auriculotemporal nerve has been described at up to $17 \%{ }^{49}$

Besides general complications of the local anesthetic such as overdosage and intranervous or vascular injection, there are specific complications described in the literature following a field or direct nerve block (Table 1). Direct injection of a 
local anesthetic in the cerebral ventricular system leading to a total subarachnoid block has been observed ${ }^{50}$ which can be a direct lethal complication when not recognized and treated promptly by protecting the airway and providing circulatory support. One must be aware of the risks of patients who have undergone craniotomy before or who have skull defects for other reasons like plasmocytoma. However, in a meta-analysis of seven studies of the scalp block, no adverse events were reported. $^{27}$

Bilotta et al investigated the learning curve of seven residents in anesthesiology in order to achieve a "goodexcellent" level of competence when applying a direct nerve block. The residents achieved an "excellent" rating after carrying out 10 procedures, concluding that a total of 11 procedures was sufficient to independently perform a direct nerve block in $95 \%$ of residents. ${ }^{51}$

To conclude, an infiltration of the surgical field by the neurosurgeon is a simple, reliable and safe technique for the vast majority of the patients. However, in patients with lower body weight, or in case of longer-lasting procedures (e.g. insula tumors), or in patients undergoing re-craniotomies (where scars inhibit the spread of the anesthetic in case of a surgical field block), but also for postoperative pain treatment, a direct nerve/scalp block (performed by an anesthetist) is a valuable alternative. It can be performed with a smaller total amount of local anesthetic, but with equal or possibly even longer-lasting effect. However, the direct nerve/scalp block is technically more challenging to perform and needs more training.

\section{The use of local anesthetics to diminish autonomic responses}

In this review, we already discussed the role of local anesthetics to provide analgesia when administered via a direct nerve block, a regional field block and via intravenous administration. Another indication for the use of local anesthetics in craniotomy patients is the reduction of autonomic responses such as coughing around extubation after general anesthesia for a craniotomy. Coughing produces a rapid rise in intracranial pressure, ${ }^{52}$ which is an undesirable response in the early postoperative period. Several interventions have been studied in a study comprising 204 patients. The most effective strategies were the application of intracuff lidocaine and intravenous lidocaine $(1.5 \mathrm{mg} / \mathrm{kg}$ at the end of surgery) significantly reducing the incidence of coughing. ${ }^{53}$ Besides the prevention of coughing, lidocaine prevents the occurrence of a postoperative sore throat up to 30 hours after extubation. ${ }^{54}$ In another randomized trial, spraying the supra- and subglottic areas with lidocaine $4 \%$ gave a significant reduction of cough during tracheal extubation. ${ }^{55}$

We recommend the use of intravenous lidocaine because the topical use of lidocaine spray might weaken laryngeal reflexes and thereby enable (silent) aspiration. Furthermore, the use of lidocaine to fill the cuff of the tube is not recommended by the producers of the tube and might cause liability problems in case of a cuff leak.

Besides lidocaine, a single bolus infusion of dexmedetomidine results in a reduction of coughing and an attenuation of hemodynamic parameters during emergence from anesthesia. ${ }^{56}$ It is an interesting question how lidocaine compares to dexmedetomidine in the reduction of autonomic responses during emergence.

\section{Conclusion}

In summary, this review clearly shows the added value of local anesthetics in patients undergoing craniotomy for brain tumor resection: local infiltration of the surgical field or a direct nerve/scalp block is an effective measure to reduce postoperative pain. In case of the awake craniotomy technique, local anesthetics can be so effective that no other analgesics have to be given intraoperatively. There is insufficient scientific support to promote one local anesthesia technique as superior to the other. In our experience, both have their advantages. Infiltration of the surgical field is easy to perform, effective and safe in most patients. Direct nerve/ scalp block has clear advantages in patients with lower body weight, longer-lasting ( $>5$ hours) procedures and possibly in re-craniotomies, but requires more training and good anatomical knowledge. Finally, in case of general anesthesia for brain tumor resection, the intravenous application of lidocaine before extubation can help to suppress coughing and hemodynamic instability leading to a smoother and better recovery from anesthesia.

Future research should focus on 1) imaging techniques, which help with the identification of smaller nerves for direct nerve blocks, and 2) local anesthetics providing a long-lasting effect with low toxicity. Finally, studies directly comparing a surgical field block versus a direct nerve/scalp block are also highly required.

\section{Disclosure}

The authors report no conflicts of interest in this work.

\section{References}

1. De Benedictis A, Moritz-Gasser S, Duffau H. Awake mapping optimizes the extent of resection for low-grade gliomas in eloquent areas. Neurosurgery. 2010;66(6):1074-1084. 
2. Hervey-Jumper SL, Berger MS. Technical nuances of awake brain tumor surgery and the role of maximum safe resection. J Neurosurg Sci. 2015;59(4):351-360.

3. Hansen E, Seemann M, Zech N, Doenitz C, Luerding R, Brawanski A. Awake craniotomies without any sedation: the awake-awake-awake technique. Acta Neurochir. 2013;155(8):1417-1424.

4. Talke PO, Gelb AW. Postcraniotomy pain remains a real headache! Eur J Anaesthesiol. 2005;22(5):325-327.

5. Guilkey RE, Ah Von D, Carpenter JS, Stone C, Draucker CB. Integrative review: postcraniotomy pain in the brain tumour patient. J Adv Nurs. 2016;72(6):1221-1235.

6. Klimek M, Ubben JFH, Ammann J, Borner U, Klein J, Verbrugge SJC. Pain in neurosurgically treated patients: a prospective observational study. J Neurosurg. 2006;104(3):350-359.

7. Gottschalk A, Berkow LC, Stevens RD, et al. Prospective evaluation of pain and analgesic use following major elective intracranial surgery. J Neurosurg. 2007;106(2):210-216.

8. Chowdhury T, Garg R, Sheshadri V, et al. Perioperative factors contributing the post-craniotomy pain: a synthesis of concepts. Front Med. 2017;4(2):150-155.

9. Molnár L, Simon É, Nemes R, Fülesdi B, Molnár C. Postcraniotomy headache. J Anesth. 2013;28(1):102-111.

10. de Gray LC, Matta BF. Acute and chronic pain following craniotomy: a review. Anaesthesia. 2005;60(7):693-704.

11. Dunn LK, Naik BI, Nemergut EC, Durieux ME. Post-craniotomy pain management: beyond opioids. Curr Neurol Neurosci Rep. 2016;16(10):93.

12. Vadivelu N, Kai A, Tran D, Kodumudi G, Legler A, Ayrian E. Options for perioperative pain management in neurosurgery. J Pain Res. 2016;9:37-47.

13. Kotak D, Cheserem B, Solth A. A survey of post-craniotomy analgesia in British neurosurgical centres: time for perceptions and prescribing to change? Br J Neurosurg. 2009;23(5):538-542.

14. Flexman AM, Ng JL, Gelb AW. Acute and chronic pain following craniotomy. Curr Opin Anaesthesiol. 2010;23(5):551-557.

15. Gee JR, Ishaq Y, Vijayan N. Postcraniotomy headache. Headache. 2003;43(3):276-278.

16. Rocha-Filho PAS. Post-craniotomy headache: a clinical view with a focus on the persistent form. Headache. 2015;55(5):733-738

17. Hagan KB, Bhavsar S, Raza SM, et al. Enhanced recovery after surgery for oncological craniotomies. J Clin Neurosci. 2016;24:10-16.

18. Geze S, Yilmaz AA, Tuzuner F. The effect of scalp block and local infiltration on the haemodynamic and stress response to skull-pin placement for craniotomy. Eur J Anaesthesiol. 2009;26(4):298-303.

19. Bloomfield EL, Schubert A, Secic M, Barnett G, Shutway F, Ebrahim ZY. The influence of scalp infiltration with bupivacaine on hemodynamics and postoperative pain in adult patients undergoing craniotomy. Anesth Analg. 1998;87(3):579-582.

20. Levin R, Hesselvik JF, Kourtopoulos H, Vavruch L. Local anesthesia prevents hypertension following application of the Mayfield skull-pin head holder. Acta Anaesthesiol Scand. 1989;33(4):277-279.

21. Chaki T, Sugino S, Janicki PK, et al. Efficacy and safety of a lidocaine and ropivacaine mixture for scalp nerve block and local infiltration anesthesia in patients undergoing awake craniotomy. $J$ Neurosurg Anesthesiol. 2016;28(1):1-5.

22. Piccioni F, Fanzio M. Management of anesthesia in awake craniotomy. Minerva Anestesiol. 2008;74(7-8):393-408.

23. Stevanovic A, Rossaint R, Veldeman M, Bilotta F, Coburn M. Anaesthesia management for awake craniotomy: systematic review and meta-analysis. PLoS One. 2016;11(5):e0156448.

24. Delion M, Terminassian A, Lehousse T, et al. Specificities of awake craniotomy and brain mapping in children for resection of supratentorial tumors in the language area. World Neurosurg. 2015;84(6): 1645-1652.

25. Klimek M, Verbrugge SJC, Roubos S, van der Most E, Vincent AJ, Klein J. Awake craniotomy for glioblastoma in a 9-year-old child. Anaesthesia. 2004;59(6):607-609.
26. Garavaglia MM, Das S, Cusimano MD, et al. Anesthetic approach to highrisk patients and prolonged awake craniotomy using dexmedetomidine and scalp block. J Neurosurg Anesthesiol. 2014;26(3):226-233.

27. Guilfoyle MR, Helmy A, Duane D, Hutchinson PJA. Regional scalp block for postcraniotomy analgesia. Anesth Analg. 2013;116(5):1093-1102.

28. Hansen MS, Brennum J, Moltke FB, Dahl JB. Pain treatment after craniotomy. Eur J Anaesthesiol. 2011;28(12):821-829.

29. Law-Koune J-D, Szekely B, Fermanian C, Peuch C, Liu N, Fischler M. Scalp infiltration with bupivacaine plus epinephrine or plain ropivacaine reduces postoperative pain after supratentorial craniotomy. $J$ Neurosurg Anesthesiol. 2005;17(3):139-143.

30. Batoz H, Verdonck O, Pellerin C, Roux G, Maurette P. The analgesic properties of scalp infiltrations with ropivacaine after intracranial tumoral resection. Anesth Analg. 2009;109(1):240-244

31. Song J, Li L, Yu P, Gao T, Liu K. Preemptive scalp infiltration with $0.5 \%$ ropivacaine and $1 \%$ lidocaine reduces postoperative pain after craniotomy. Acta Neurochir. 2015;157(6):993-998.

32. Akcil EF, Dilmen OK, Vehid H, Ibisoglu LS, Tunali Y. Which one is more effective for analgesia in infratentorial craniotomy? The scalp block or local anesthetic infiltration. Clin Neurol Neurosurg. 2017;154:98-103.

33. Zhou H, Ou M, Yang Y, Ruan Q, Pan Y, Li Y. Effect of skin infiltration with ropivacaine on postoperative pain in patients undergoing craniotomy. Springerplus. 2016;5(1):1180.

34. Kranke P, Jokinen J, Pace NL, et al. Continuous intravenous perioperative lidocaine infusion for postoperative pain and recovery. Cochrane Database Syst Rev. 2015;(7):CD009642.

35. Peng Y, Zhang W, Kass IS, Han R. Lidocaine reduces acute postoperative pain after supratentorial tumor surgery in the PACU: a secondary finding from a randomized, controlled trial. J Neurosurg Anesthesiol. 2016;28(4):309-315.

36. Kerscher C, Zimmermann M, Graf BM, Hansen E. Kraniale leitungsanästhesien: hilfreiche techniken für neurochirurgie, dermatologie, plastische chirurgie und schmerztherapie [Scalp blocks. A useful technique for neurosurgery, dermatology, plastic surgery and pain therapy]. Anaesthesist. 2009;58(9):949-958; quiz 959-960. German [with English abstract].

37. Cohen-Gadol A, Kemp W III, Tubbs R. The innervation of the scalp: a comprehensive review including anatomy, pathology, and neurosurgical correlates. Surg Neurol Int. 2011;2(1):178-176.

38. Papangelou A, Radzik BR, Smith T, Gottschalk A. A review of scalp blockade for cranial surgery. J Clin Anesth. 2013;25(2):150-159.

39. Osborn I, Sebeo J. "Scalp block" during craniotomy: a classic technique revisited. J Neurosurg Anesthesiol., 2010;22(3):187-194.

40. Cuzalina AL, Holmes JD. A simple and reliable landmark for identification of the supraorbital nerve in surgery of the forehead: an in vivo anatomical study. J Oral Maxillofacial Surg. 2005;63(1):25-27.

41. Janis JE, Hatef DA, Hagan R, et al. Anatomy of the supratrochlear nerve: implications for the surgical treatment of migraine headaches. Plast Reconstr Surg. 2013;131(4):743-750.

42. Janis JE, Hatef DA, Thakar H, et al. The zygomaticotemporal branch of the trigeminal nerve: Part II. Anatomical variations. Plast Reconstr Surg. 2010;126(2):435-442.

43. Jeong SM, Park KJ, Kang SH, et al. Anatomical consideration of the anterior and lateral cutaneous nerves in the scalp. J Korean Med Sci. 2010;25(4):517-522.

44. Tubbs RS, Salter EG, Wellons JC, Blount JP, Oakes WJ. Landmarks for the identification of the cutaneous nerves of the occiput and nuchal regions. Clin Anat. 2006;20(3):235-238.

45. Greher M, Moriggl B, Curatolo M, Kirchmair L, Eichenberger U. Sonographic visualization and ultrasound-guided blockade of the greater occipital nerve: a comparison of two selective techniques confirmed by anatomical dissection. Br J Anaesth. 2010;104(5):637-642.

46. Jayaram K, Srilata M, Kulkarni D, Ramachandran G. Regional anesthesia to scalp for craniotomy: innovation with innervation. J Neurosurg Anesthesiol. 2016;28(1):32-37.

47. Millay DJ, Larrabee WF, Carpenter RL. Vasoconstrictors in facial plastic surgery. Arch Otolaryngol Head Neck Surg. 1991;117(2):160-163. 
48. de Jong RH, Bonin JD. Mixtures of local anesthetics are no more toxic than the parent drugs. Anesthesiology. 1981;54(3):177-181.

49. McNicholas E, Bilotta F, Titi L, Chandler J, Rosa G, Koht A. Transient facial nerve palsy after auriculotemporal nerve block in awake craniotomy patients. AA Case Rep. 2014;2(4):40-43.

50. Yanagi F, Kano T. Accidental total subarachnoid block following local scalp anesthesia. J Anesth. 1996;10(1):66-68.

51. Bilotta F, Titi L, Lanni F, Stazi E, Rosa G. Training anesthesiology residents in providing anesthesia for awake craniotomy: learning curves and estimate of needed case load. J Clin Anesth. 2013;25(5):359-366.

52. Williams B. Cerebrospinal fluid pressure changes in response to coughing. Brain. 1976;99(2):331-346.
53. Soltani HA, Aghadavoudi O. The effect of different lidocaine application methods on postoperative cough and sore throat. $J$ Clin Anesth. 2002;14(1):15-18.

54. Tanaka Y, Nakayama T, Nishimori M, Tsujimura Y, Kawaguchi M, Sato Y. Lidocaine for preventing postoperative sore throat. Cochrane Database Syst Rev. 2015;(7):CD004081.

55. D'Aragon F, Beaudet N, Gagnon V, Martin R, Sansoucy Y. The effects of lidocaine spray and intracuff alkalinized lidocaine on the occurrence of cough at extubation: a double-blind randomized controlled trial. Can J Anesth/J Can Anesth. 2013;60(4):370-376.

56. Guler G, Akin A, Tosun Z, Eskitascoglu E, Mizrak A, Boyaci A. Singledose dexmedetomidine attenuates airway and circulatory reflexes during extubation. Acta Anaesthesiol Scand. 2005;49(8):1088-1091.
Local and Regional Anesthesia

\section{Publish your work in this journal}

Local and Regional Anesthesia is an international, peer-reviewed, open access journal publishing on the development, pharmacology, delivery and targeting and clinical use of local and regional anesthetics and analgesics. The journal is included in PubMed, and welcomes submitted papers covering original research, basic science, clinical studies,

\section{Dovepress}

reviews and evaluations, guidelines, expert opinion and commentary, case reports and extended reports. The manuscript management system is completely online and includes a very quick and fair peer-review system, which is all easy to use. Visit http://www.dovepress.com/ testimonials.php to read real quotes from published authors. 